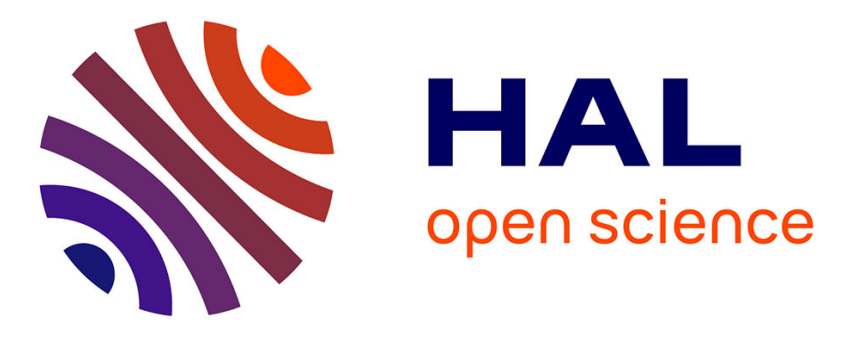

\title{
Molecular linkage maps: strategies, resources and achievements
}

Guido Cipriani, Gabriele Di Gaspero, Aurelie A. Canaguier, Julie Jusseaume, Johan Tassin, Arnaud Lemainque, Vincent Thareau, Anne-Francoise A.-F. Adam-Blondon, Raffaele Testolin

\section{To cite this version:}

Guido Cipriani, Gabriele Di Gaspero, Aurelie A. Canaguier, Julie Jusseaume, Johan Tassin, et al.. Molecular linkage maps: strategies, resources and achievements. Genetics, Genomics and Breeding of Crop Plants, Sciences Publishers, 390 p., 2011, 978-1-57808-717-4. hal-02806958

\section{HAL Id: hal-02806958 https://hal.inrae.fr/hal-02806958}

Submitted on 6 Jun 2020

HAL is a multi-disciplinary open access archive for the deposit and dissemination of scientific research documents, whether they are published or not. The documents may come from teaching and research institutions in France or abroad, or from public or private research centers.
L'archive ouverte pluridisciplinaire HAL, est destinée au dépôt et à la diffusion de documents scientifiques de niveau recherche, publiés ou non, émanant des établissements d'enseignement et de recherche français ou étrangers, des laboratoires publics ou privés. 


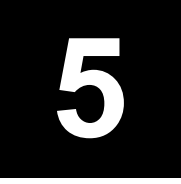

\title{
Molecular Linkage Maps: Strategies, Resources and Achievements
}

\author{
Guido Cipriani, ${ }^{1, *}$ Gabriele Di Gaspero, ${ }^{1,2}$ Aurélie Canaguier, ${ }^{3}$ \\ Julie Jusseaume, ${ }^{3}$ Johan Tassin, ${ }^{4}$ Arnaud Lemainque, ${ }^{4,6}$ \\ Vincent Thareau, ${ }^{5}$ Anne-Françoise Adam-Blondon ${ }^{3}$ \\ and Raffaele Testolin ${ }^{1,2}$
}

\begin{abstract}
The development of genetic maps in grapevine started in the late 90s. It greatly benefited from the development of SSR markers by an international consortium, leading to the construction of integrated genetic maps. Software was improved for facilitating map construction in full sib families. A review of the different strategies that were developed for mapping in grapevine, including mapping populations, software and markers is provided here together with a discussion on their interest and limitations. Thanks to all these resources and experience, genetic mapping is now easy to handle in grapevine and is now widely used for QTL detection, map-based cloning, comparative mapping across species and genome sequence anchoring.
\end{abstract}

Keywords: Genetic map, SSR, SNP, integrated map, full-sib family, heterozygosity

${ }^{1}$ Dipartimento di Scienze Agrarie e Ambientali, University of Udine, via delle scienze 208, 33100 Udine, Italy.

${ }^{2}$ Istituto di Genomica Applicata, Parco Scientifico e Tecnologico, via Jacopo Linussio 51, 33100, Udine, Italy.

${ }^{3}$ UMR INRA UEVE ERL CNRS Génomique Végétale, 2 rue Gaston Crémieux, BP 5708, 91057 Evry cedex, France.

${ }^{4}$ Centre National de Génotypage, CNG-IG CEA, 2 rue Gaston Crémieux CP 5721, 91057 Evry Cedex, France.

${ }^{5}$ IBP, UMR CNRS Université Paris-Sud, bat 630, 91405 Orsay cedex, France.

${ }^{6}$ Present address: IMAGENE, Bat Genavenir 6, Genopole campus 1, 5 rue Henri Desbruères, 91030 Evry cedex, France.

*Corresponding author: guido.cipriani@uniud.it 


\subsection{Introduction}

Genetic maps based on molecular markers emerged on the scene of plant genetics in the 1980s (Beckmann and Soller 1983; Tanksley et al. 1989) and in the course of time became indispensable tools for grapevine geneticists.

In perennials, the development of the first genetic maps occurred later than in annuals due to the higher difficulty of generating large progeny from controlled crosses (e.g., Tulsieram et al. 1992) and to the difficulty of extracting large amounts of high quality DNA, which was required for the production of the first-generation molecular markers, such as restriction fragment length polymorphism (RFLP) markers (e.g., Lodhi et al. 1994). The first grapevine linkage map was constructed in 1995 (Lodhi et al. 1995), while the first genetic maps in tomato and maize were published in 1986 and 1988, respectively (Bernatzky and Tanksley 1986; Helentjaris et al. 1988).

Genetic mapping provided significant benefit to the grapevine community only after the development of molecular markers based on polymerase chain reaction (PCR). In parallel, improvement of statistical methods and software required for handling segregation data in various genetic contexts (full-sib families, back-crosses, $\mathrm{F}_{2}$ ) were regularly achieved.

In the following paragraphs we will review how and when molecular markers were introduced in grapevine genetics, the evolution of grapevine linkage maps, as well as the algorithms and mapping populations used.

\subsection{Evolution of Molecular Markers for Genetic Mapping: from RFLPs to SNPs}

The development and use of molecular markers in grape followed the development of molecular biology that began in the 1970s. Initially, markers were used for the analysis of genetic diversity in the grapevine germplasm (see Chapter 2).

\subsubsection{Isozymes}

Isoenzymes became very popular in the 1980s as markers capable of discriminating grape accessions and to confirm parentage (Loukas et al. 1983; Arulsekar and Parfitt 1986). Segregation data provided by this kind of biochemical marker can be found in the first grapevine linkage maps (Lodhi et al. 1995; Dalbò et al. 2000; Doligez et al. 2002; Grando et al. 2003).

\subsubsection{RFLP}

The first kind of DNA-based molecular markers that came into play for genetic mapping was RFLP marker (Beckmann and Soller 1983). RFLP 
markers have never received the same attention from grape breeders as they got for instance in humans and in other crop species. This was mainly due to the high cost of using this technique, the large amount of DNA required, and the necessity to access and store large collections of probes. Most of these probes were heterologous, that is developed from the DNA of other plant species. In spite of these technical constraints, RFLP contributed to the construction of the earliest grape maps (Lodhi et al. 1995; Dalbò et al. 2000; Doligez et al. 2002; Grando et al. 2003).

\subsubsection{RAPD, AFLP, SAMPLE, and S-SAP}

The first revolution in grape molecular genetics took place with the advent of the PCR technique and the use of arbitrarily designed primers that do not require a priori knowledge of the DNA sequence of the species of interest (Williams et al. 1990). Random amplified polymorphic DNA (RAPD; Williams et al. 1990) markers were easy to produce, and their cost was affordable in terms of labor and investment, even in small laboratories.

In grapevine, RAPD markers were used in several maps (Lodhi et al. 1995; Lahogue et al. 1998; Dalbò et al. 2000), but they were very quickly replaced by another type of marker produced with a combination of endonucleases and arbitrarily designed primers: the amplified fragment length polymorphism (AFLP) marker (Vos et al. 1995). AFLPs were more reproducible and yielded a greater number of polymorphic loci per experiment, with a single gel displaying as many as one hundred different bands per lane, a dozen of which could segregate in a mapping population. AFLP-based linkage maps were produced between 2002 and 2007 (Doligez et al. 2002; Grando et al. 2003; Doucleff et al. 2004; Fischer et al. 2004; Riaz et al. 2004; Cabezas et al. 2006; Troggio et al. 2007).

Both RAPD and AFLP markers have several drawbacks, such as dominance, reproducibility issues, and low transportability across distantly related genotypes. The latter is a severe limitation, as geneticists and especially breeders frequently need to share knowledge acquired in a particular mapping population with others.

Two marker classes, based on the AFLP technology and thus showing the same major drawbacks, deserve mentioning, although their use was mostly aimed at distinguishing grape accessions rather than at producing linkage maps: selective amplification of polymorphic loci (SAMPL), which combines the AFLP technology with the abundance and polymorphism of simple sequence repeat (SSR) markers, and sequence-specific amplified polymorphism (S-SAP), in which the AFLP technology is combined with the retrotransposon long terminal repeat (LTR) (Pelsy et al. 2003; Labra et al. 2004; Pelsy 2007). A single paper reports the use of SAMPL and S-SAP markers in grapevine mapping (Cabezas et al. 2006). 


\subsubsection{SSR}

RAPD, AFLP, and their derived classes of markers were never adopted in humans, where genetic maps were initially produced using RFLP and then microsatellite or SSR markers. A highly saturated linkage map based on 5,264 SSRs was published in 1996 to anchor the human physical map in the frame of the Human Genome Sequencing project (Dib et al. 1996).

Microsatellite repeats are also abundant in plant genomes, and show a preferential distribution to non-repetitive regions (Morgante et al. 2002). They are amplified as single loci in diploid genomes, they are codominant, and are highly polymorphic in grapevine (see for, e.g., Aradhya et al. 2003). In addition, they have conserved flanking regions that make them transferable to related species (Moore et al. 1991), which is particularly true within the Vitaceae family (Sefc et al. 1999; Di Gaspero et al. 2000; Decroocq et al. 2003). All of these positive features made them the ideal markers for the construction of linkage maps that are transferable from one cross to another.

The SSR markers were first isolated in grapevine in the early 1990s (Thomas and Scott 1993; Bowers et al. 1996; Bowers et al. 1999). During the International Conference on Grape Genetics and Breeding in 1998 held at Montpellier (France), Mark Thomas, Carol Meredith, and Patrice This launched the Vitis Microsatellite Consortium (VMC), a project aiming to develop a large number of microsatellite markers under the coordination of Agrogene, SA. The proposal stimulated the cooperative effort of numerous institutions called to sequence groups of 48 cloned fragments produced by Agrogene from grape genomic libraries, enriched with 10 different types of di- and tri-nucleotide repeats. This work resulted in the production of nearly 1,000 SSR markers. Several hundreds of these markers were polymorphic and segregated in mapping populations (Doligez et al. 2002; Grando et al. 2003; Adam-Blondon et al. 2004; Fisher et al. 2004; Mandl et al. 2006; Riaz et al. 2006; Di Gaspero et al. 2007). Since $90 \%$ of the VMC SSRs were AG repeats, several institutions produced new genomic libraries enriched for different repeats, which were used to isolate a substantial number of new SSRs (Sefc et al. 2000; Lefort et al. 2002; Di Gaspero et al. 2005; Merdinoglu et al. 2005), while other groups isolated new SSRs from expressed sequence tag (EST) collections (Scott et al. 2000; Decroocq et al. 2003; Riaz et al. 2006). An added advantage of SSR markers is that several of them can be multiplexed by different dyes and by adjacent allele range sizes, and analyzed in a single run with an automatic sequencer, increasing the throughput of the analysis (Merdinoglu et al. 2005). After the completion of the grapevine genome sequencing projects, several thousand SSR markers became available and retrievable from the NCBI database with simple programs like Sputnik (http://cbi.labri.fr/outils/Pise/sputnik.html). The most abundant class of SSRs 
in the grapevine genome are di-nucleotide repeats, representing $46 \%$ of the total 75,185 SSRs identified so far. Tri-, tetra-, and penta-nucleotide repeats are also cumulatively well represented in the genome, but the relative frequency of each individual type of repeat is low, except for AAT $(19 \%)$, AAAT (10\%), and AAAT (0.07\%; Table 5-1).

A set of SSR markers with 3-nt to 5-nt core repeat, the type of choice in human forensics, were selected for covering all grapevine chromosomes and validated for their power of discrimination among individuals (Cipriani et al. 2008), in view of their potential use in grapevine fingerprinting (Cipriani et al. 2010).

Table 5-1 SSR markers identified in the $12 \mathrm{X}$ assembly of the PN40024 grape genome sequence (Jaillon et al. 2007) using a modified version of the Sputnik software (http://cbi.labri.fr/ outils/ Pise/ sputnik.html.

\begin{tabular}{ccrc}
\hline Type of repeat & $\begin{array}{c}\text { Average repeat length } \\
(\mathrm{bp})^{\text {a }}\end{array}$ & $\begin{array}{c}\text { No. of } \\
\text { occurrences }\end{array}$ & $\begin{array}{c}\text { Fraction } \\
\text { of the total }\end{array}$ \\
\hline di-nucleotide & 12.02 & 34,449 & 0.46 \\
-AT & 14.09 & 23,674 & 0.31 \\
-AG/CT & 13.00 & 8,349 & 0.11 \\
-AC/GT & 12.01 & 2,423 & 0.03 \\
- CG & 9.00 & 3 & 0.00 \\
tri-nucleotide & 7.47 & 18,747 & 0.25 \\
-AAT & 9.08 & 14,522 & 0.19 \\
-AAG & 8.01 & 1,982 & 0.03 \\
-ATC & 7.09 & 710 & 0.01 \\
-ACC & 7.08 & 486 & 0.01 \\
-AAC & 7.07 & 363 & 0.00 \\
-others & 7.27 & 684 & 0.01 \\
tetra-nucleotide & 5.68 & 11,279 & 0.15 \\
-AAAT & 5.07 & 7,715 & 0.10 \\
-AAAG & 5.08 & 862 & 0.01 \\
-AATT & 5.04 & 721 & 0.01 \\
-ACAT & 7.03 & 470 & 0.01 \\
-AATC & 5.06 & 446 & 0.01 \\
-others & 5.73 & 1,065 & 0.01 \\
penta-nucleotide & 4.08 & 10,710 & 0.14 \\
-AAAAT & 4.05 & 5,623 & 0.07 \\
-AAAAG & 4.06 & 1,809 & 0.02 \\
-AAATT & 4.04 & 651 & 0.01 \\
-AAAAC & 4.06 & 525 & 0.01 \\
-AATAT & 4.05 & 348 & 0.00 \\
-others & 4.09 & 75,185 & 1.00 \\
TOTAL & 6.94 & 1754 & \\
\hline
\end{tabular}

${ }^{a}$ Minimum no. of repeat fixed for each search: 8 for di-nucleotide repeats, 6 for tri-nucleotide repeats, 5 for tetra-nucleotide repeats, and 4 for penta-nucleotide repeats. 
All these sets of SSR markers are listed in Table 5-2, and most of them are available in public databases (see Chapter 13).

Table 5-2 Grapevine SSR markers listed according to their date of publication.

\begin{tabular}{lcccl}
\hline Code & $\begin{array}{c}\text { No. of } \\
\text { sequences }\end{array}$ & Type of repeat & Source (a) & Reference \\
\hline VVS & 5 & GA and GT & EGL & Thomas and Scott 1993 \\
VVMD & 4 & mainly CT & EGL & Bowers et al. 1996 \\
VVMD & 22 & CT & EGL & Bowers et al. 1999 \\
ssrVrZAG & 18 & GA & EGL & Sefc et al. 1999 \\
scu[xx]vv & 10 & 2- and 3-nt & EST & Scott et al. 2000 \\
ssrVvUCH & 7 & mainly AG & EGL & Lefort et al. 2002 \\
VVC & 8 & CA and CA & EST & Decroocq et al. 2003 \\
VMC, VMCNg & 357 & mainly AG & EGL & Agrogene, unpublished (b) \\
VVI & 169 & various & EGL & Merdinoglu et al. 2005 \\
UDV & 108 & AC & EGL & Di Gaspero et al. 2005 \\
ctg, CF, AF, BM, VEST & unknown & unknown & EST & Riaz et al. 2006 \\
uncoded & 239,634 & all & SG & Jaillon et al. 2007 \\
VChr & 38 & 3- to 5-nt & SG & Cipriani et al. 2008 \\
\hline
\end{tabular}

(a) EGL, Enriched genomic libraries; EST, Expressed sequence tag libraries; SG, Shot-gun sequencing.

(b) Partially published in Di Gaspero et al. 2000; Pellerone et al. 2001; Adam-Blondon et al. 2004; Arroyo-Garcia and Martinez-Zapater 2004; Riaz et al. 2004; Goto-Yamamoto et al. 2006; deposited in NCBI STS database.

\subsubsection{SNP}

Single nucleotide polymorphism (SNP) markers are the most recently developed class of markers. They target a single base mutation in the DNA sequence. Small indels (insertion or deletion events) are also assimilated as SNP markers since they can be handled with many of the technologies designed to identify SNPs. Their discovery relies on resequencing the same DNA region from different haplotypes. In grapevine, two research groups sequenced 25 and 230 gene fragments in 9 and 11 Vitis vinifera genotypes, respectively and observed a frequency of one SNP every 47 to $64 \mathrm{bp}$ (Salmaso et al. 2004; Lijavetzky et al. 2007). Sequencing the heterozygous Pinot Noir led to the discovery of one SNP every $250 \mathrm{bp}$, by comparing the two haplotypes (Velasco et al. 2007), however, a significant amount of variation in this frequency exists along the genome: from one SNP/60 bp to one SNP/250 bp or less. Authors estimated that the number of potential SNP markers in the Pinot Noir genome could reach 2 million, with many present in coding regions, covering approximately $87 \%$ of annotated genes (Velasco et al. 2007).

SNPs are easily amenable to massive parallel automatic detection (Rapley and Harbron 2004; Steemers et al. 2006), making them particularly useful for saturating maps, especially in coding regions (Pindo et al. 2008), 
or as an approach to gene discovery through linkage disequilibrium studies. Lijavetzky et al. (2007) estimated an $83 \%$ success rate for the conversion of a candidate variable nucleotide position into a technically scorable SNP marker. This conversion rate fell to $61 \%$ when SNPs were initially identified in the Pinot Noir sequence without resequencing any additional genotype (Pindo et al. 2008; Vezzulli et al. 2008a). Some 30\% of SNP markers developed from sequencing $V$. vinifera cultivars are estimated to be heterozygous in any other $V$. vinifera cultivar (Lijavetzky et al. 2007; Vezzulli et al. 2008a). This rate could fall to $19 \%$ in feral accessions of $V$. vinifera and to $2 \%$ in wild species (Vezzulli et al. 2008b).

The transferability of SNPs across species is, therefore, much less likely than the transferability of SSRs and this is a major issue in mapping many traits, such as those for resistance to biotic and abiotic stress which usually entail genes present in wild species. However, due to their high density in the grapevine genome and the flexibility of multiplexing systems, it is possible to envisage working with complementary sets of SNP markers, some of which could be informative in $V$. vinifera and others in wild relatives, as it has been proposed for rice (http://mlorieux.free.fr/Rice_Genomics/Research/ RiceDiversity/CoreMap/index.html).

Next-generation sequencing technologies now allow to rapidly identify customized sets of SNPs, for maximizing the informative content of the DNA chip in the gene pool of interest or in the parents of mapping populations. Accurate filtering of true SNPs from sequencing and alignment errors is still a challenging step, before embarking on a SNP chip experiment for linkage mapping. More confidence on this issue was generated by a case study of Myles et al. (2010), in which a 9K SNP array design from a set of $71 \mathrm{~K}$ high-quality SNPs provided $97.7 \%$ concordance between genotype calls from the sequencing data and from the DNA chip.

\subsection{Mapping Populations and Mapping Strategies}

As mentioned above, perennial species pose specific biological problems in the development of mapping populations. The generation time is long (3-5 years from seed to seed), growing many individuals is cost and labor demanding, species are heterozygous, and several of them, grapevine included, are sensitive to inbreeding depression (Einset and Pratt 1975). Yet, large cross populations can be prepared without the limits of animal brood sizes.

The genetic structure of the mapping population and the dominant/ co-dominant nature of the markers are the two factors that determine the observed genotypic classes and the information provided by each individual of the family (Allard 1956). 
Traditionally, linkage studies in plants are carried out using the classical test cross, where two phenotypically or genotypically contrasting inbred lines are crossed to produce an $\mathrm{F}_{1}$, which in turn is either backcrossed to one of the parents resulting in a 1:1 segregation of markers, or selfed to produce an $\mathrm{F}_{2}$, resulting in a 1:2:1 segregation of co-dominant markers and a 3:1 segregation of dominant markers. Ritter et al. (1990) proposed the formulas for calculating the linkage between different classes of markers (dominant, co-dominant, with or without null allele) segregating in $F_{1}$ families obtained from heterozygous parents. In the case of dominant markers, the segregation of markers heterozygous in either parent is the same as in a classical backcross or testcross. This approach was adopted in 1994 by Grattapaglia and Sederoff to produce a linkage map of Eucalyptus species based on dominant RAPD markers (Grattapaglia and Sederoff 1994). They named this type of mapping approach the "pseudo-testcross". Lodhi et al. (1995) introduced such a "pseudo-testcross" in grapevine, which was widely used for the construction of RAPD- and AFLP-based maps (Table 5-3). However, the drawback of this strategy is that the correspondence between the homologous linkage groups in the two parents can not be established. It can only be established through markers that are heterozygous in both parents and segregate in a ratio of 3:1 (Ritter et al. 1990; Lodhi et al. 1995). Co-dominant markers, such as SSR markers, that often have segregating alleles from both parents, provide a better solution to bridging homologous linkage groups, and have been widely used for that reason since 2003 (Table 5-3). From this point of view, SNP markers are in most cases bi-allelic (Troggio et al. 2007; Vezzulli et al. 2008a), segregate from a single parent like in the pseudo-testcross, and do not contribute to the identification of homologous linkage groups.

In grapevine, mapping populations usually consist of full-sib families $\left(\mathrm{F}_{1}\right)$ derived from a cross between two highly heterozygous parents, but some have also been produced by selfing a single genotype (Table 5-3). This unexpectedly reduced segregation biases (Adam-Blondon et al. 2004; Duchêne et al. 2009), with the percentage of segregating markers falling to around $50 \%$ against $75 \%$ of markers segregating in a typical full-sib family. Parents of biparental populations were chosen for their high heterozygosity and loose genetic relatedness with the objective of minimizing the occurrence of common alleles, which hampers the identification of which parent transmits them to the progeny and in turn makes them less informative. Contrasting phenotypes for the trait(s) to be mapped are also necessary factors in the choice of parents, in order to follow the inheritance of the trait in the progeny.

The number of meioses, and thus the size of the progeny, necessary to reach an acceptable level of precision in the estimation of the genetic distance between two markers depends on the informative content of the markers, 
Molecular Linkage Maps: Strategies, Resources and Achievements

119

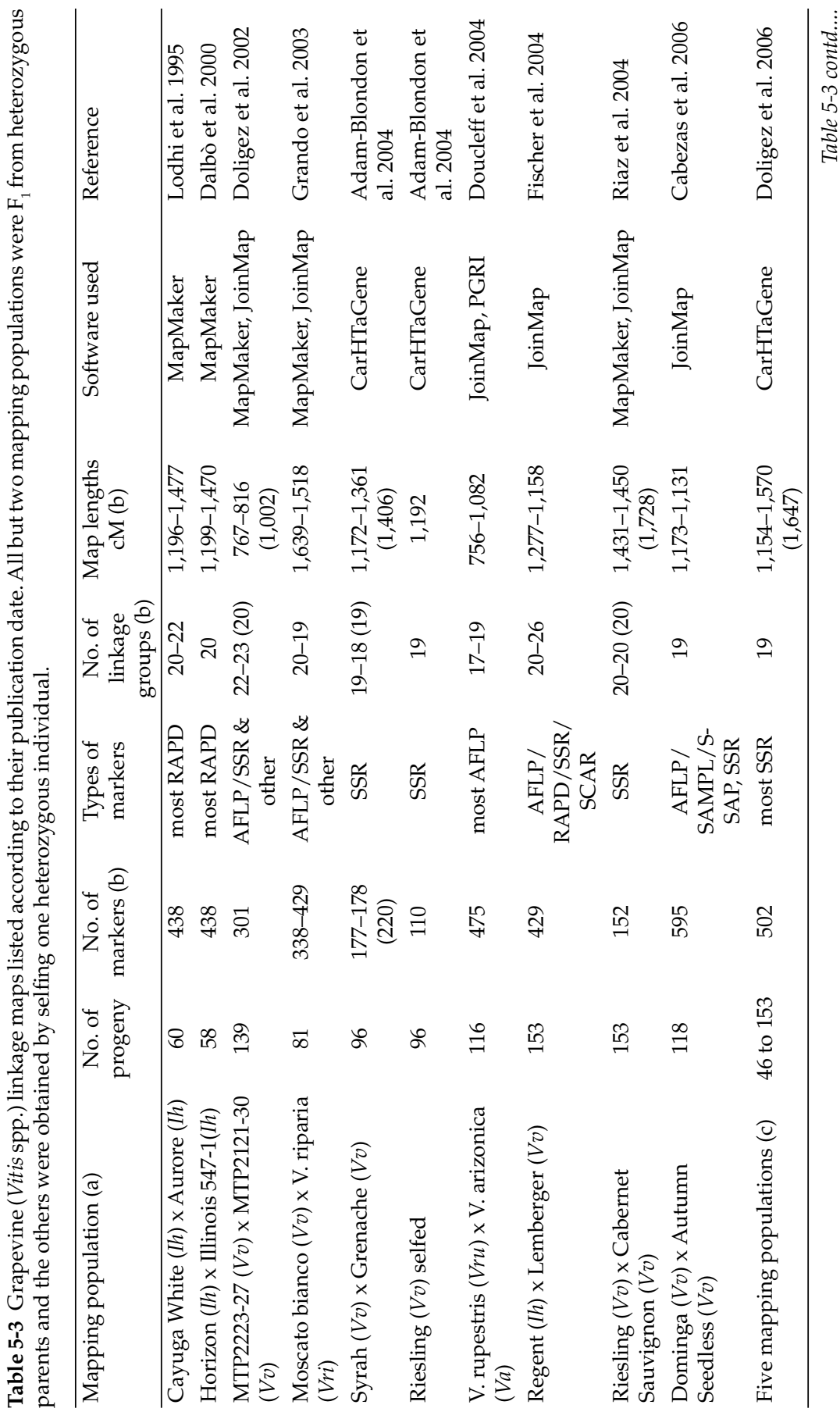




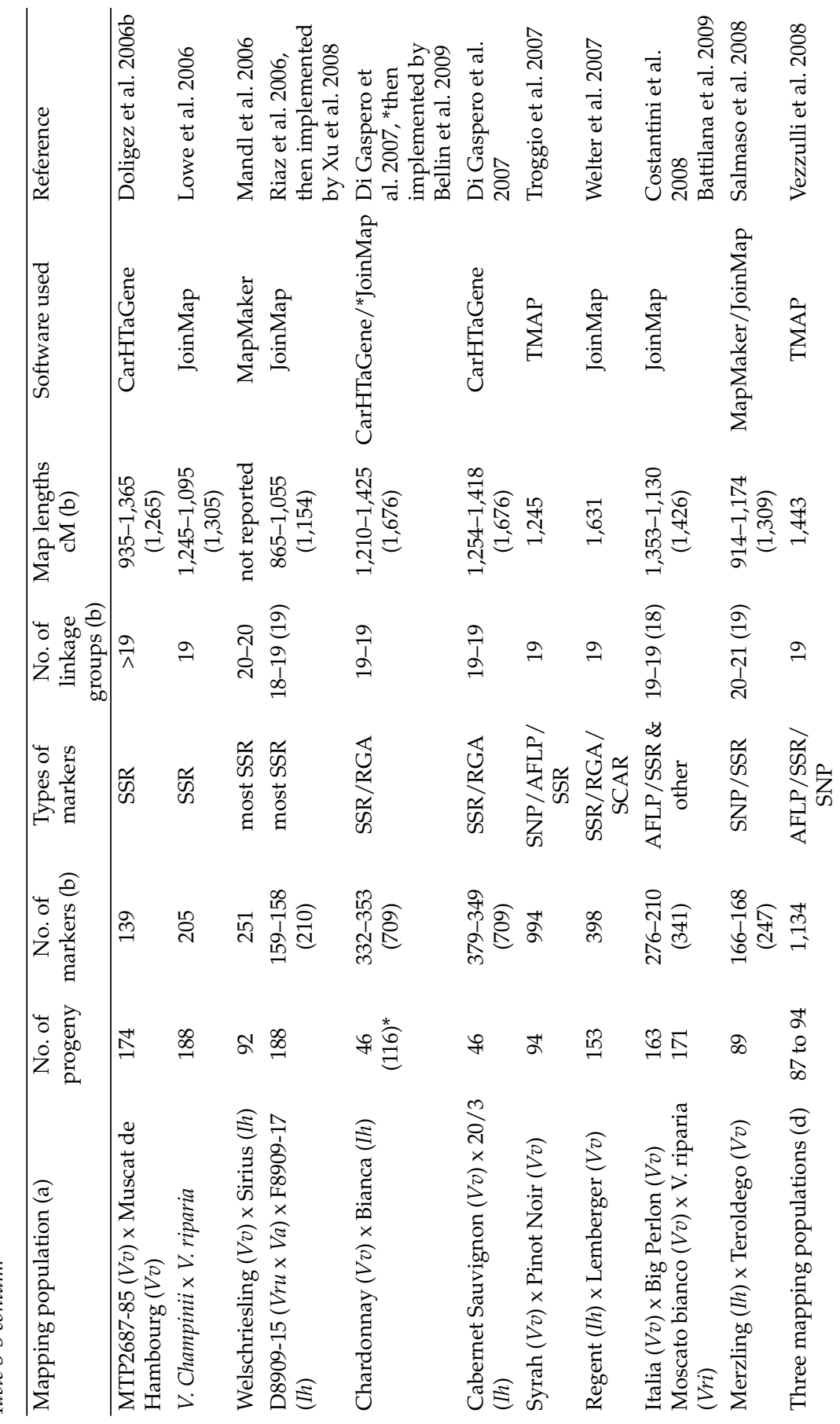




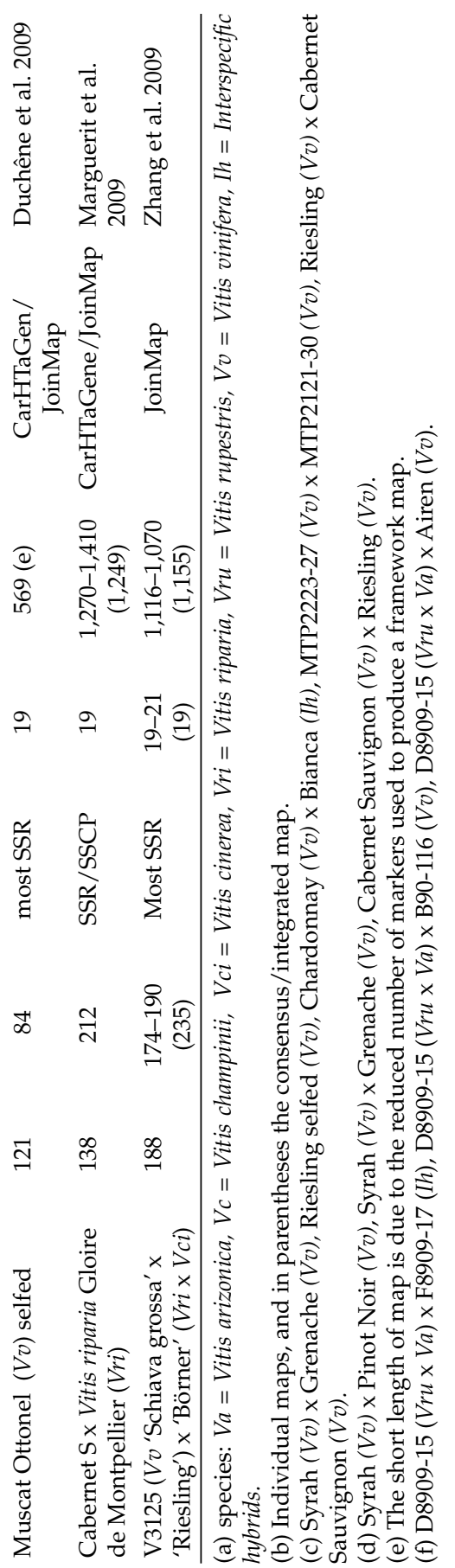


which can be highly variable in an $\mathrm{F}_{1}$ family depending on the segregation type (Ritter et al. 1990). The size of mapping populations in grape has ranged from 46 to 181 individuals, with most maps based on a number of individuals close to 100 . Such a progeny size is a good compromise, in order to avoid inflation of the cost of map production while still providing enough statistical strength for the estimation of the correct marker order and distances. It also depends on the objective of the mapping project. For instance, to quickly get a genome-wide picture of marker order for as many markers as possible, it is possible to combine mapping data from two or more populations (Di Gaspero et al. 2007; Doligez et al. 2006a), sometimes very small (46 individuals in Di Gaspero et al. 2007). This trick allowed the mapping of an extraordinarily high proportion of markers in at least one parent $(91 \%)$, while only 75 and $80 \%$ of total markers would have segregated in either population separately (Di Gaspero et al. 2007). Hence, although the two mapping populations were of limited size, the number of informative meioses per marker was 46 to 184, and 130 on average, depending on the heterozygosity of the parents for each marker (Di Gaspero et al. 2007). This high number of informative meioses per marker mitigated the conflicts in finding the most likely linear order of markers (Doligez et al. 2006a; Di Gaspero et al. 2007; Vezzulli et al. 2008a). The drawbacks of this strategy will be discussed later. When the purpose of mapping is to identify a trait locus, marker orders and estimation of genetic distances can be refined around the locus, once the chromosomal region controlling a trait of interest has been identified, by adding markers designed on the homologous region in the reference genome sequence and by using additional individuals of the same or related mapping populations (Riaz et al. 2008; Bellin et al. 2009; Coleman et al. 2009; Hwang et al. 2010; Di Gaspero and Cattonaro 2010).

\subsection{Mapping Algorithms and Software Used}

The process of map construction can be separated into three phases: identification of groups of linked markers, ordering these markers, and estimation of the genetic distance between two adjacent markers. Of these tasks, the second is the most challenging. The ways in which these issues

have been addressed in the construction of genetic maps in grapevine is discussed in the following paragraphs.

\subsubsection{Individual Parental Maps}

Whatever the type of marker used (dominant or co-dominant), it is possible to follow the segregation of heterozygous markers in either parent of an $\mathrm{F}_{1}$ population like in a backcross population, and to construct two independent maps (Lodhi et al. 1995; Dalbo et al. 2000). If the population is derived from 
a selfed individual, then the segregation behaves like a $\mathrm{F}_{2}$ (Adam-Blondon et al. 2004; Duchêne et al. 2009).

The first very popular software adopted by plant geneticists and then by grape geneticists, was MapMaker (Lander et al. 1987). MapMaker calculates the probabilities of association between markers and the probabilities of marker order by the maximum likelihood approximation (Allard 1956; Lander et al. 1987). To handle the marker phase, some authors have suggested a strategy which consists of duplicating the whole set of data, inverting the allele code in the duplicated matrix, and merging the two mirror datasets. The program then constructs groups of linked markers and each group has a mirror group that is removed from the subsequent analyses. This strategy was first used in woody plants by Grattapaglia and Sederoff (1994) and in grape by Lodhi et al. (1995). Marker distances are finally calculated using functions that take into account the non-additive nature of mapping distances when they are large (Haldane 1919; Kosambi 1944).

\subsubsection{Consensus Map from the Two Parental Segregations of a Cross}

When a high number of co-dominant markers segregating in both parents are available, it is possible to construct a single consensus map from the genotypic dataset of the $F_{1}$ family, and the software must process heterogeneous types of segregation as described in Ritter et al. (1990). This kind of dataset cannot be handled by MapMaker. JoinMap is the first popular software that was developed for this purpose (Stam and Van Ooijen 1995; Van Ooijen and Voorrips 2001).

JoinMap automatically calculates the phase of the markers before conducting linkage analysis for full-sib families. Version 4.0 of the program includes either the classical maximum likelihood or a new Monte Carlo maximum likelihood algorithm (ML). The latter is very fast in computation and can easily make calculations from large sets of markers (100 or more) per linkage group (Van Ooijen 2006). Unfortunately it cannot be used for out-breeding full-sib families, which are the most commonly used populations in grapevine (Table 5-3). An original algorithm was developed for the calculation of distances between markers (Stam 1993). Fifteen papers report the use of different versions of JoinMap to produce linkage maps in grapevine (Table 5-3). Such popularity is likely due to the flexibility in handling different marker segregations and the user-friendly interface.

CarHTaGene is mentioned in six papers (Table 5-3) and was the second most popular software used in grapevine. TMAP was the last software to be adopted (documented in two papers listed in Table 5-3). TMAP but not CarHTaGene calculates the phase of the alleles, but both of them 
can build consensus maps with or without the assumption of conserved recombination ratios across different individuals (de Givry et al. 2005; Cartwright et al. 2007). In both, marker ordering is based on a Monte Carlo algorithm to find the maximum multipoint-likelihood order with automated heuristic methods for testing the orders and managing missing data (several in CarHTaGene and one in TMAP; Scheix and Gaspin 1997; de Givry et al. 2005; Carthwright et al. 2007). CarHTaGene is the only one among the three packages managing outbred populations that gives scientists the option of choosing between different final orders. However, this package is computationally more power-demanding. TMAP is the only package that calculates a probability of error for each marker, which is accounted for in the calculation of the maximum likelihood of the map order (Cartwright et al. 2007). The efficient removal of false double recombination has been shown to reduce map inflation. Finally, from a more practical point of view, TMAP is able to read data files compatible with MapMaker, JoinMap, and CarHTaGene, and has very useful procedures for automatic transformation of the data matrix (for parental maps, consensus maps, etc.) that does not exist in the other packages.

The simultaneous use of segregation from both parents is advantageous when one wants to compile a unique map, which consists of markers alternatively heterozygous in either parent, and also wants to increase the number of informative meioses for the estimate of marker distance. In the process of integrating maps, the way in which an analyst copes with heterogeneous recombination rates and with duplicated marker loci is crucial for the correct reconstruction of marker order. Low resolution due to genotype-specific suppression of recombination in one parent is compensated by the crossovers that could have occurred in the other parent. Recombination rates are averaged over the two individuals, thus providing a more reliable expectation for any other genotype of the species. If this is desirable at a genome wide level, it may be misleading for predicting the efficiency for marker-assisted selection of alleles linked to a trait in a certain parent. Integrated maps tend to wobble in regions with a low density of common markers, in stretches of linked markers with distorted segregation in one parent, and across segmental duplications in which duplicated markers are heterozygous in the two parents at either locus.

\subsubsection{Integration of Maps developed from Different Populations}

As the first SSR-based genetic maps became available, they were soon merged into single consensus maps (Doligez et al. 2006a; Vezzulli et al. 2008a). In this case, the problem is handling data sets where the segregation type can be heterogeneous not only between markers, but also within markers. JoinMap, CarHTaGene, and TMAP can all handle such data. The 
integrated map is constructed with different algorithms depending on the software used, which may lead to different outputs. Several papers describe the difference between the outputs of JoinMap and CarHTaGene (Scheix and Gaspin 1997; Doligez et al. 2006a).

Merging maps is very attractive because it provides a snapshot of the markers available at a given chromosomal region, but such consensus maps have some inherent weaknesses. For instance, map distances are less accurate if only a few markers are shared among individual maps, and map length is inflated by genotyping errors that add up. Also, the location of "private" markers, which are markers segregating in only one or a few parents tends to wobble, and their distance from common markers is not defined (Doligez et al. 2006a). These drawbacks are mainly due to the unbalanced number of meioses used to calculate the recombination among pairs of markers, which creates friction in the estimate of map distances. In some instances, instead of merging datasets, it would be preferable to build individual maps based on specific recombination rates, and then to align them using common markers, thus bringing markers mapped in different individuals into a unique map by a projection of distances (Arcade et al. 2004).

\subsection{Different Generation of Maps in the Vitaceae}

To date, genetic maps have been developed only in the Vitis genus, with several aims: QTL detection, physical map/chromosome anchoring, and map based cloning.

\subsubsection{Maps Based on Anonymous Markers}

The first grapevine linkage map was produced by the research group based at the Geneva Experimental Station in the United States (Lodhi et al. 1995). The mapping population was an $F_{1}$ obtained by crossing two highly heterozygous interspecific hybrids produced by the same research group, Cayuga White and Aurore, and consisted of 60 progeny. The authors were able to place 428 markers in total, mostly RAPD, and the maps resulted in 20 and 22 linkage groups, with total lengths of 1,196 and 1,477 cM, respectively (Table 5-3). The markers, being dominant, segregated from either parent and were recorded as presence/absence of amplified bands. MapMaker was adopted for the association analysis and construction of the linear series of markers along each linkage group. Lodhi's map was developed as an exercise for showing the potential of molecular markers in rapidly saturating genetic maps, without the need for hundreds of phenotypic characters. It is mentioned here for its historical value, being the first map ever produced in grape and the first application of the pseudo-testcross method in this species. 
Several other maps were developed mainly from RAPD or AFLP markers, with a progressive introduction of SSR markers as they became available from the Vitis Microsatellite Consortium (e.g., Doligez et al. 2002; Grando et al. 2003). The main objective of these maps was to quickly cover all of the chromosomes of both parents in order to detect QTLs for traits of interest (e.g., Doligez et al. 2002; Fischer et al. 2004; Cabezas et al. 2006; Welter et al. 2007; Costantini et al. 2008). Some single locus traits were also mapped, such as the main locus for berry color and the locus controlling flower sex (Dalbò et al. 2000; Doligez et al. 2002).

\subsubsection{Maps Based on SSR and SNP Markers}

The publication of the first map completely developed from SSR markers was in 2004 (Riaz et al. 2004). Many genetic maps were published later, based mainly, if not exclusively, on SSR markers (Adam-Blondon et al. 2004; Fisher et al. 2004; Mandl et al. 2006; Riaz et al. 2006; Di Gaspero et al. 2007; Welter et al. 2007). SSR markers allowed the unification of linkage group numbering (Riaz et al. 2004; Adam-Blondon et al. 2004) and the definition of sets of markers located at regular intervals, suited for comparative QTL detection, and highly heterozygous across the existing maps. Some improvement is expected in the near future by defining an additional group of markers to better cover the chromosomal extremities and a few remaining gaps (Doligez et al. 2006a). This may require new marker development, as the main problem in these areas has been the homozygosity of the parents for the markers available (Doligez et al. 2006a). The genome sequence will help to provide many targeted candidates. The grape genome is very heterozygous on average, but some regions contain homozygous blocks that are not covered by informative markers (Velasco et al. 2007). It is still unclear if localized low heterozygosity occurred specifically and by chance in the few genotypes in which it was noticed, or if it is a common feature with a biological significance in certain regions across the genotypes.

The first map predominantly based on SNP markers appeared in 2007 (Troggio et al. 2007). The authors observed a non-random distribution of the SNP markers derived from non-coding regions (BAC-end sequences), whereas SNPs derived from coding regions were randomly distributed, like SSR markers. This map is also the most dense genetic map based on a single population (average distance between two markers of $1.3 \mathrm{cM}$ ), with 615 transferable markers (483 SNP and 132 SSR) and 379 AFLP markers (Troggio et al. 2007). It spans a 1,245-cM genome length, which means that $1 \mathrm{cM}$ would correspond to $390 \mathrm{~kb}$ on average, although the correlation between genetic and physical distances is variable across the genome 
(Lamoureux et al. 2006; Troggio et al. 2007). A comparison between the SSRbased linkage map of linkage group 2 from Doligez (Doligez et al. 2006a) and the same linkage group based on SSR and SNP markers published by Vezzulli (Vezzulli et al. 2008a) is shown in Fig. 5-1.

Finally, SSR markers and SNPs have also allowed gene mapping in grapevine, with a strong emphasis on candidate genes for disease resistance (Di Gaspero et al. 2007; Welter et al. 2007), as well as other traits (Salmaso et al. 2008), and targeting genes has allowed the development of markers that are more transferable across species (Lowe and Walker 2006).

\subsubsection{Use of Linkage Maps in Genome Sequencing Projects}

Genetic maps with dense saturation and high resolution are fundamental tools in genome sequencing projects to assist the anchorage of the genome sequence to the chromosomes, and as such, the Doligez et al. (2006a) and Vezzulli et al. (2008a) integrated maps were used to anchor respectively the 8.4X assembly of the PN40024 (Jaillon et al. 2007) and the Pinot Noir (Velasco et al. 2007) genome sequences, respectively.

Recently, an improved version of the Doligez et al. (2006a) map has been produced in order to anchor and order the sequence scaffolds of the final PN40024 12X assembly, by increasing the size of two mapping populations, and by genotyping a well chosen set of markers in each of them: 358 individuals of the Chardonnay $x$ Bianca population were scored with 379 SSR markers, and 179 individuals of the Syrah $\times$ Grenache population were scored with 325 SSR markers (unpublished data). The two consensus maps were constructed using Tmap, and the Syrah $x$ Grenache map was projected onto the Chardonnay $x$ Bianca population using Biomercator (Arcade et al. 2004). The resulting integrated map has 514 SSR markers, 174 of them newly developed from BAC-end sequencing and scaffold sequences, and is presented in Fig. 5-2.

While the sequence assembly of the nearly homozygous genotype PN40024 made use of genetic map information mainly for anchoring ready-to-map sequence scaffolds (Jaillon et al. 2007), the assembly of the heterozygous Pinot Noir sequence required marker information to assist the sequence assembler in the construction of metacontigs, sorting out chimeric metacontigs that merged contigs from different linkage groups (Velasco et al. 2007). The linkage map was also used to find the metacontigs position and orientation. SNP markers were then developed on sequence contigs with unassigned map position and placed back onto the genetic map (Troggio et al. 2007; Velasco et al. 2007; Vezzulli et al. 2008a). 
128 Genetics, Genomics and Breeding of Grapes

A

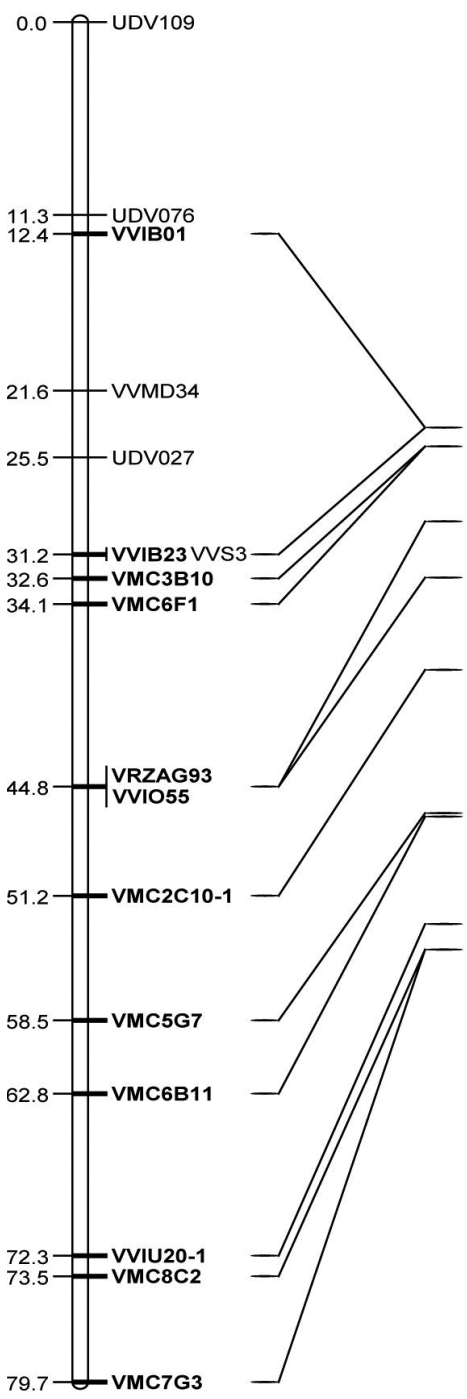

B

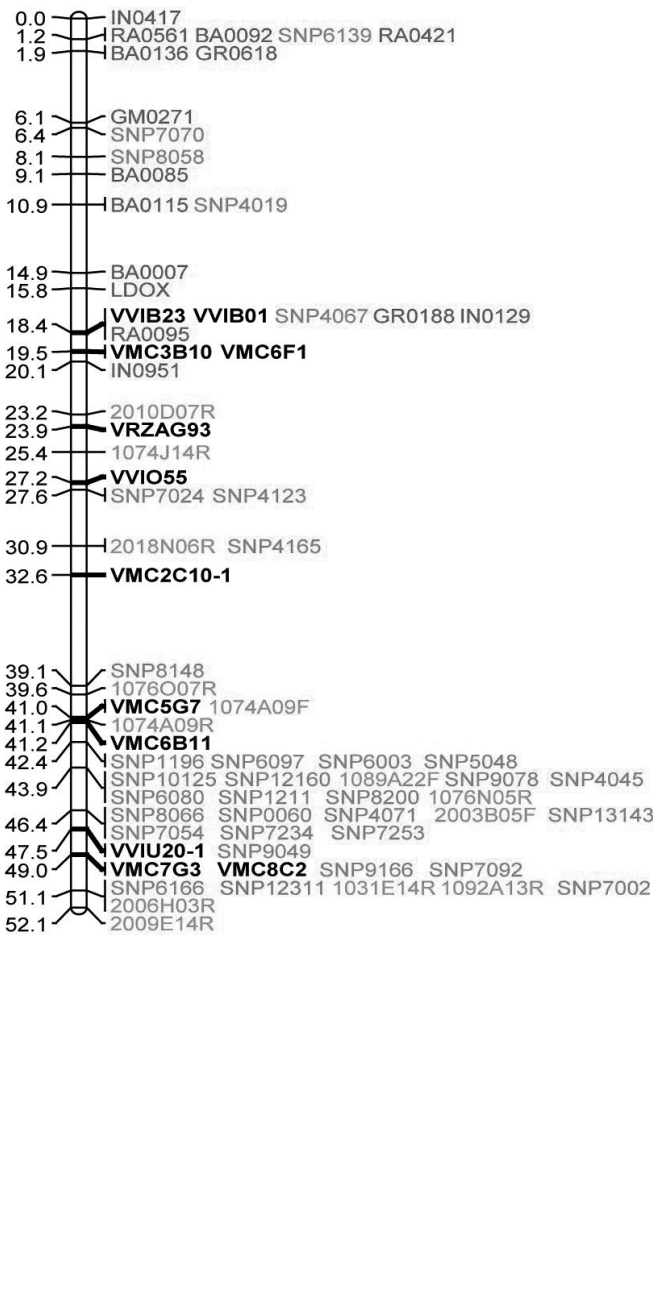

1.2 TRA0561 BA0092 SNP6139 RA042

14.97 BA000

18.4 VVIB23 VVIB01 SNP4067GR0188IN0129

$19.5-1$ VMC3B10 VMC6F1
- GM0271

12018

Figure 5-1 Grapevine linkage map of chromosome 2. (A) Reference map based exclusively on SSR markers (Doligez et al. 2006a); (B) the same linkage group saturated with SNP markers (Vezzulli et al. 2008a). SSR markers common to both maps are connected by lines. EST-derived SNPs are in red; BES-derived SNPs are in green (from Troggio et al. 2007); SNPs based on the heterozygous sites in the Pinot Noir sequence are in cyan (Velasco et al. 2007).

Color image of this figure appears in the color plate section at the end of the book. 

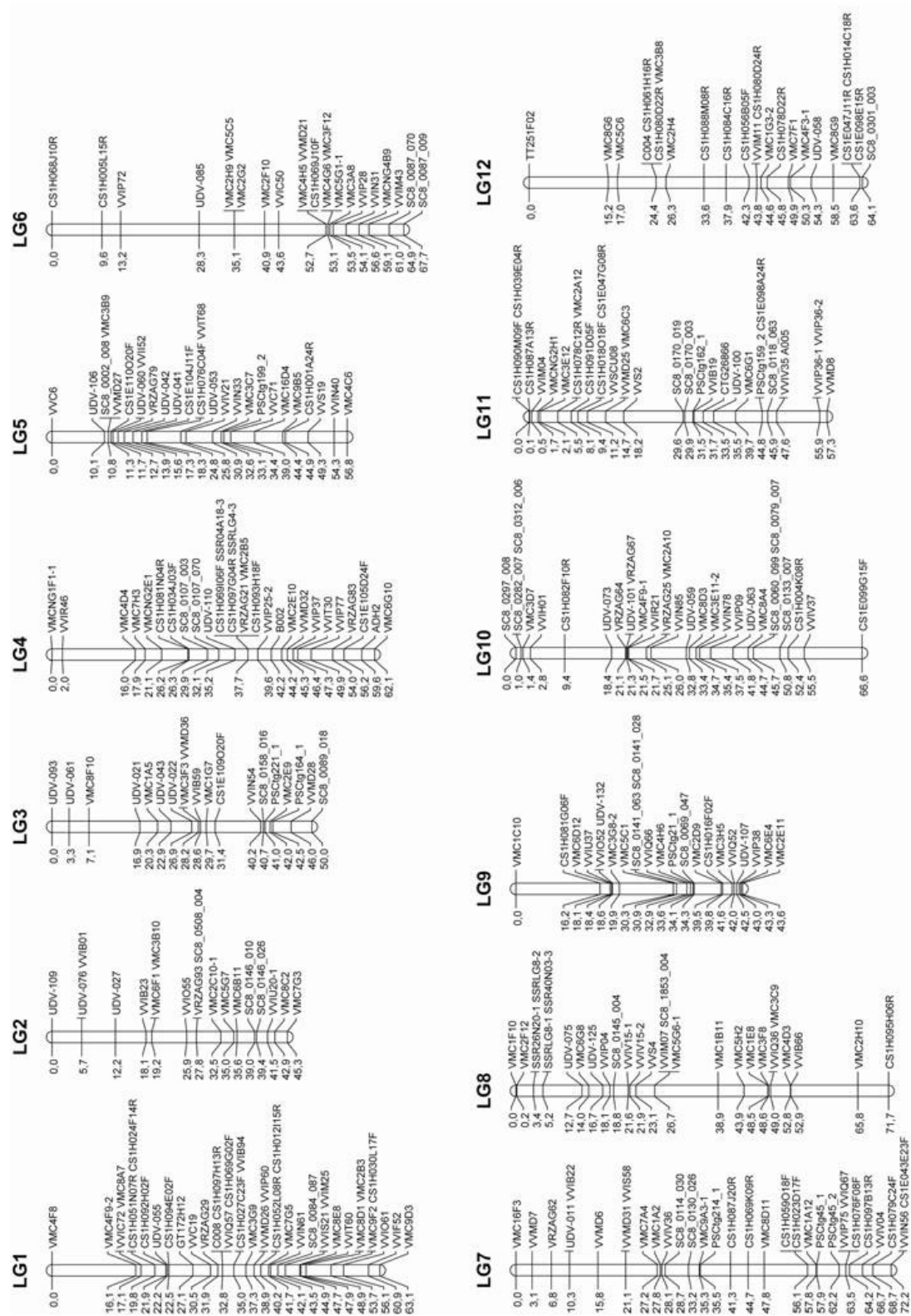
130 Genetics, Genomics and Breeding of Grapes

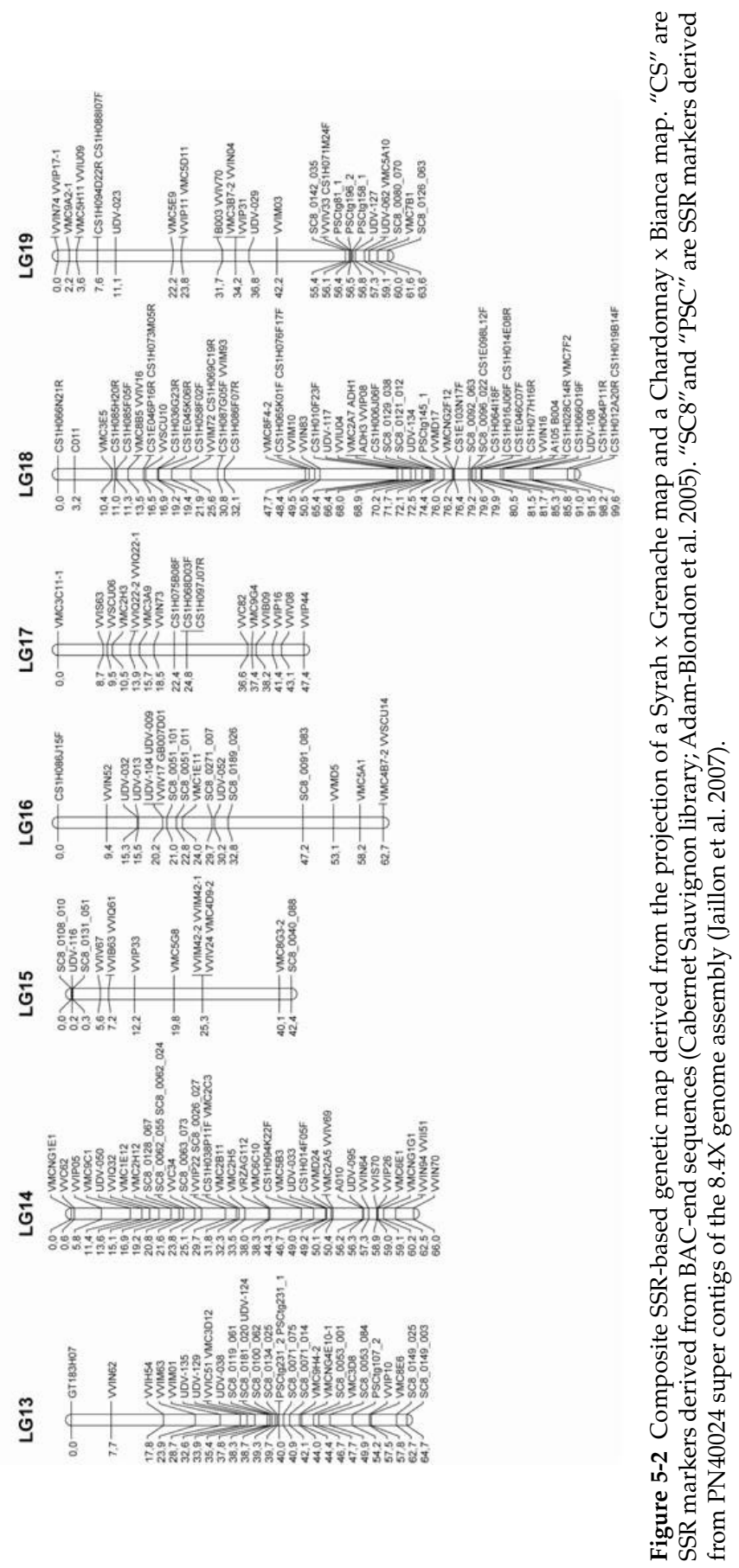




\subsubsection{Comparative Genetic Mapping across the Vitaceae}

Local marker order and estimation of their relative distances are occasionally inconsistent across different maps, but most of the time these discrepancies involve closely linked markers or markers for which the most probable order is not clear (see Doligez et al. 2006a; Di Gaspero et al. 2007; and Vezzulli et al. 2008a for discussion). The possibility of mis-ordering due to local heterogeneity in recombination rates between individuals, to genotyping errors, to intra-chromosomal segmental duplications, or to regions with skewed segregation ratio is discussed in Doligez et al. 2006a; Lowe and Walker 2006; Di Gaspero et al. 2007; and Riaz et al. 2008. Frequently, these points of attrition are associated with markers embedded into intrachromosomal segmental duplications or regions with tandemly arrayed genes (Doligez et al. 2006a; Di Gaspero et al. 2007).

Despite small local deviations from conservation of marker order, grape genetic maps are easily compared and there is so far no evidence of major disruption of synteny either between species of the genus Vitis (Grando et al. 2003; Doucleff et al. 2004, Lowe et al. 2006; Welter et al. 2007; Riaz et al. 2008) or within Vitis vinifera (Doligez et al. 2006a; Vezzulli et al. 2008a). One region with a distorted segregation on chromosome 14 was consistently found across several populations. Riaz et al. (2008) proposed that this region might contain gametophytic factors and called it V-SDR1 for Vitis-Segregation Disorder Region 1.

The main use of genetic maps is to find the chromosomal region where the genetic determinants of any qualitative or quantitative trait reside. This goal may be initially achieved with a minimal set of evenly spaced markers. Some 150-200 markers covering the entire grape genome are enough for detecting the large linkage blocks, transmitted by the parents to a biparental mapping population. Once the region of interest is identified one can select sequence scaffolds anchored by the markers of the region of interest, and develop new markers in the sequence that will be used in turn to saturate the map. The methods and issues associated to map-based cloning are discussed in Chapter 8. The annotated grapevine genome can aid in the search for genetic determinants of phenotypic traits. The two-pronged process of jumping from the genetic map to the sequence scaffolds (and back) helps to integrate the positional cloning strategy with the candidate gene approach as exemplified by the linkage maps used to find the candidate gene for terpenol biosynthesis (Battilana et al. 2008; Duchêne et al. 2009) or for the powdery mildew resistance gene at the REN1 locus (Coleman et al. 2009). 


\section{Acknowledgements}

The authors are indebted to Courtney Coleman of the Missouri State University for revision of the manuscript. They thank also Isabelle Le Clainche and Audrey Weber for the technical assistance; Riccardo Velasco, Michela Troggio and Sivia Vezzulli of Fondazione Edmund Mach for the unpublished markers and the map of linkage group 2 included in Fig. 5-1 and Agnès Doligez and Thomas Scheix for discussions on mapping softwares.

\section{References}

Adam-Blondon AF, Roux C, Claux D, Butterlin G, Merdinoglu D, This P (2004) Mapping 245 SSR markers on the Vitis vinifera genome: a tool for grape genetics. Theor Appl Genet 109: 1017-1027.

Allard RW (1956) Formulas and tables to facilitate the calculation of recombination values in heredity. Hilgardia 24: 235-278.

Aradhya MK, Dangl GS, Prins BH, Boursiquot JM, Walker MA, Meredith CP, Simon CJ (2003) Genetic structure and differentiation in cultivated grape, Vitis vinifera L. Genet Res 81: 179-192.

Arcade A, Labourdette A, Falque M, Mangin B, Chardon F, Charcosset A, Joets J (2004) BioMercator: integrating genetic maps and QTL towards discovery of candidate genes. Bioinformatics 20: 2324-2326.

Arroyo-Garcia R, Martinez-Zapater JM (2004) Development and characterization of new microsatellite markers for grape. Vitis 4: 175-178.

Arulsekar S, Parfitt DE (1986) Isozyme analysis procedures for stone fruits, almond, grape, walnut, pistachio, and fig. HortScience 21: 928-933.

Battilana J, Costantini L, Emanuelli F, Sevini F, Segala C, Moser S, Velasco R, Versini G, Grando MS (2009) The 1-deoxy-D: -xylulose 5-phosphate synthase gene co-localizes with a major QTL affecting monoterpene content in grapevine. Theor Appl Genet 118: 653-669.

Beckmann JS, Soller M (1983) RFLP in genetic improvement: methodologies, mapping and costs. Theor Appl Genet 67: 35-43.

Bellin D, Peressotti E, Merdinoglu D, Wiedemann-Merdinoglu S, Adam-Blondon AF, Cipriani G, Morgante M, Testolin R, Di Gaspero G (2009) Resistance to Plasmopara viticola in grapevine 'Bianca' is controlled by a major dominant gene causing localised necrosis at the infection site. Theor Appl Genet 20: 163-176.

Bernatzky R, Tanksley SD (1986) Toward a saturated linkage map in tomato based on isozymes and random cDNA sequences. Genetics 112: 887-898.

Bowers JE, Dangl GS, Vignani R, Meredith CP (1996) Isolation and characterization of new polymorphic simple sequence repeat loci in grape (Vitis vinifera L.). Genome 39: 628-633.

Bowers JE, Dangl GS, Meredith CP (1999) Development and characterization of additional microsatellite DNA markers for grape. Am J Enol Vitic 50: 243-246.

Cabezas JA, Cervera MT, Ruiz-Garcia L, Carreno J, Martinez-Zapater JM (2006) A genetic analysis of seed and berry weight in grapevine. Genome 49: 1572-1585.

Cartwright DA, Troggio M, Velasco R, Gutin A (2007) Genetic mapping in the presence of genotyping errors. Genetics 176: 2521-2527.

Cipriani G, Marrazzo MT, Di Gaspero G, Pfeiffer A, Morgante M, Testolin R (2008) A set of microsatellite markers with long core repeat optimized for grape (Vitis spp.) genotyping. BMC Plant Biol 8: 127.

Cipriani G, Spadotto A, Jurman I, Di Gaspero G, Crespan M, Meneghetti S, Frare E, Vignani R,Cresti M, Morgante M, Pezzotti M, Pè E, Policriti A, Testolin R (2010) The SSR-based 
molecular profile of 1005 grapevine (Vitis vinifera L.) accessions uncovers new synonymy and parentages, and reveals a large admixture among varieties of different geographic origin. Theor Applied Genet: in press.

Coleman C, Copetti D, Cipriani G, Hoffmann S, Kozma P, Kovács L, Morgante M, Testolin R, Di Gaspero G (2009) The powdery mildew resistance gene REN1 co-segregates with an NBS-LRR gene cluster in two Central Asian grapevines. BMC Genet 10: 89.

Costantini L, Battilana J, Lamaj F, Fanizza G, Grando MS (2008) Berry and phenology-related traits in grapevine (Vitis vinifera $\mathrm{L}$.): from quantitative trait loci to underlying genes. BMC Plant Biol 8: 38.

Dalbò MA, Ye G-N, Weeden NF, Steinkellner H, Sefc KM, Reisch BI (2000) A gene controlling sex in grapevines place on a molecular marker-based genetic map. Genome 43: 333-340.

de Givry S, Bouchez M, Chabrier P, Milan D, Schiex T (2005) CarthaGene: multipopulation integrated genetic and radiation hybrid mapping. Bioinformatics 21: 1703-1704.

Decroocq V, Favè MG, Hagen L, Bordenave L, Decroocq S (2003) Development and transferability of apricot and grape EST microsatellite markers across taxa. Theor Appl Genet 106: 912-922.

Dib C, Fauré S, Fizames C, Samson D, Drouot D, Vignal A, Millasseau P, Marc S, Kazan J, Seboun E, Lathrop M, Gyapay G, Morissette J, Weissenbach J (1996) A comprehensive genetic map of the human genome based on 5,264 microsatellites. Nature 380: 152-154.

Di Gaspero G, Cattonaro F (2010) Application of genomics to grapevine improvement. Austr J Grape Wine Res 16: 122-130.

Di Gaspero G, Peterlunger E, Testolin R, Edwards KJ, Cipriani G (2000) Conservation of microsatellite loci within the genus Vitis. Theor Appl Genet 101: 301-308.

Di Gaspero G, Cipriani G, Marrazzo MT, Andreetta D, Prado Castro MJ, Peterlunger E, Testolin $\mathrm{R}$ (2005) Isolation of (AC)n-microsatellites in Vitis vinifera L. and analysis of genetic background in grapevines under marker assisted selection. Mol Breed 15: 11-20.

Di Gaspero G, Cipriani G, Adam-Blondon AF, Testolin R (2007) Linkage maps of grapevine displaying the chromosomal locations of 420 microsatellite markers and 82 markers from R-gene candidates. Theor Appl Genet 114: 1249-1263.

Doligez A, Bouquet A, Danglot Y, Lahogue F, Riaz S, Meredith CP, Edwards KJ, This P (2002) Genetic mapping of grapevine (Vitis vinifera L.) applied to the detection of QTLs for seedlessness and berry weight. Theor Appl Genet 105: 780-795.

Doligez A, Adam-Blondon AF, Cipriani G, Di Gaspero G, Laucou V, Merdinoglu D, Meredith CP, Riaz S, Roux C, This P (2006a) An integrated SSR map of grapevine based on five mapping populations. Theor Appl Genet 113: 369-382.

Doligez A, Audiot E, Baumes R, This P (2006b) QTLs for muscat flavor and monoterpenic odorant content in grapevine (Vitis vinifera L.). Mol Breed 18: 109-125.

Doucleff M, Jin Y, Gao F, Riaz S, Krivanek AF, Walker MA (2004) A genetic linkage map of grape, utilizing Vitis rupestris and Vitis arizonica. Theor Appl Genet 109: 1178-1187.

Duchêne E, Butterlin G, Claudel P, Dumas V, Jaegli N, Merdinoglu D (2009) A grapevine (Vitis vinifera L.) deoxy-D: -xylulose synthase gene colocates with a major quantitative trait loci for terpenol content. Theor Appl Genet 118: 541-552.

Einset J, Pratt C (1975) Advances in Fruit Breeding. Purdue Univ Press, USA.

Fischer BM, Salakhutdinov I, Akkurt M, Eibach R, Edwards KJ, Töpfer R, Zyprian EM (2004) Quantitative trait locus analysis of fungal disease resistance factors on a molecular map of grapevine. Theor Appl Genet 108: 501-515.

Goto-Yamamoto N, Hiroshi M, Azumi M, Edwards KJ (2006) Development of grape microsatellite markers and microsatellite analysis including oriental cultivars. Am J Enol Vitic 57: 105-108.

Grando MS, Bellin D, Edwards KJ, Pozzi C, Stefanini M, Velasco R (2003) Molecular linkage maps of Vitis vinifera L. and Vitis riparia Mchx. Theor Appl Genet 106: 1213-1224.

Grattapaglia D, Sederoff R (1994) Genetic linkage maps of Eucalyptus grandis and Eucalyptus urophylla using a pseudo-testcross: mapping strategy and RAPD markers. Genetics 137: 1121-1137. 
Haldane JBS (1919) The combination of linkage values, and the calculation of distances between the loci of linked factors. J Genet 8: 299-309.

Helentjaris T, Weber D, Wright S (1988) Identification of the Genomic Locations of Duplicate Nucleotide Sequences in Maize by Analysis of Restriction Fragment Length Polymorphisms. Genetics 118: 353-363.

Hwang CF, Xu K, Hu R, Zhou R, Riaz S, Walker MA (2010). Cloning and characterization of $X i R 1$, a locus responsible for dagger nematode resistance in grape. Theor Appl Genet DOI: $10.1007 /$ s00122-010-1349-y.

Jaillon O, Aury J-M, Noel B, Policriti A, Clepet C, Casagrande A, Choisne N, Aubourg S, Vitulo N, Jubin C, Vezzi, A, Legeai F, Hugueney P, Dasilva C, Horner D, Mica E, Jublot D, Poulain J, Bruyere C, Billault A, Segurens B, Gouyvenoux M, Ugarte E, Cattonaro F, Anthouard V, Vico V, DelFabbro C, Alaux M, DiGaspero G, Dumas V, Felice N, Paillard S, Juman I, Moroldo M, Scalabrin S, Canaguier A, LeClainche I, Malacrida G, Durand E, Pesole G, Laucou V, Chatelet P, Merdinoglu D, Delledonne M, Pezotti M, Lecharny A, Scarpelli C, Artiguenave F, Pe ME, Valle G, Morgante M, Caboche M, Adam-Blondon A-F, Weissenbach J, Quetier F, Wincker O (2007) The grapevine genome 24 sequence suggests ancestral hexaploidization in major angiosperm phyla. Nature 449: 463-468.

Kosambi DD (1944) The estimation of map distances from recombination values. Ann Eugen 12: $172-175$.

Labra M, Imazio S, Grassi F, Rossoni M, Sala F (2004) Vine-1 retrotransposon-based sequencespecific amplified polymorphism for Vitis vinifera L. genotyping. Plant Breed 123: $180-185$.

Lahogue F, This P, Bouquet A (1998). Identification of a codominant scar marker linked to the seedlessness character in grapevine. Theor Appl Genet 97: 950-959.

Lamoureux D, Bernole A, Le Clainche I, Tual S, Thareau V, Paillard S, Legeai F, Dossat C, Wincker P, Oswald M, Merdinoglu D, Vignault C, Delrot S, Caboche M, Chalhoub B, Adam-Blondon AF (2006) Anchoring of a large set of markers onto a BAC library for the development of a draft physical map of the grapevine genome. Theor Appl Genet 113: 344-356.

Lander ES, Green P, Abrahamson J, Barlow A, Daly MJ, Lincoln SE, Newburg L (1987) MAPMAKER: an interactive computer package for constructing primary genetic linkage maps of experimental and natural populations. Genomics 1: 174-181.

Lefort F, Kyvelos CJ, Zervou M, Edwards KJ, Roubelakis-Angelakis KA (2002) Characterization of new microsatellite loci from Vitis vinifera and their conservation in some Vitis species and hybrids. Mol Ecol Notes 2: 20-21.

Lijavetzky D, Cabezas JA, Ibáñez A, Rodríguez V, Martínez-Zapater JM (2007) High throughput SNP discovery and genotyping in grapevine (Vitis vinifera L.) by combining a re-sequencing approach and SNPlex technology. BMC Genomics 8: 424.

Lodhi MA, Ye G-N, Weeden NF, Reisch BI (1994) A simple and efficient method for DNA extraction from grapevine cultivars and Vitis species. Plant Mol Biol Rep 12: 6-13.

Lodhi MA, Daly MJ, Ye GN, Weeden NF, Reisch BI (1995) A molecular marker based linkage map of Vitis. Genome 38: 786-794.

Loukas M, Stavrakakis MN, Krimbas CB (1983) Inheritance of polymorphic isoenzymes in grape cultivars. J Hered 74: 181-183.

Lowe KM, Walker MA (2006) Genetic linkage map of the interspecific grape rootstock cross Ramsey (Vitis champinii) x Riparia Gloire (Vitis riparia). Theor Appl Genet 112: $1582-1592$.

Mandl K, Santiago J-L, Hack R, Fardossi A, Regner F (2006) A genetic map of Welschriesling x Sirius for the identification of magnesium-deficiency by QTL analysis. Euphytica 149: 133-144.

Marguerit E, Boury C, Manicki A, Donnart M, Butterlin G, Némorin A, Wiedemann-Merdinoglu S, Merdinoglu D, Ollat N, Decroocq S (2009) Genetic dissection of sex determinism, inflorescence morphology and downy mildew resistance in grapevine. Theor Appl Genet 118: 1261-1278. 
Merdinoglu D, Butterlin G, Bevilacqua L, Chiquet V, Adam-Blondon AF, Decroocq S (2005) Development and characterization of a large set of microsatellite markers in grapevine (Vitis vinifera L.) suitable for multiplex PCR. Mol Breed 15: 349-366.

Moore SS, Sargeant LL, King TJ, Mattick JS, Georges M, Hetzel DJS (1991) The conservation of dinucleotide microsatellites among mammalian genomes allows the use of heterologous PCR primer pairs in closely related species. Genomics 10: 654-660.

Morgante M, Hanafey M, Powell W (2002) Microsatellites are preferentially associated with nonrepetitive DNA in plant genomes. Nat Genet 30: 194-200.

Myles S, Chia JM, Hurwitz B, Simon C, Zhong GY, Buckler E, Ware D (2010) Rapid genomic characterization of the genus Vitis. PLoS One 5(1): e8219.

Pauquet J, Bouquet A, This P, Adam-Blondon AF (2001) Establishment of a local map of AFLP markers around the powdery mildew resistance gene Run 1 in grapevine and assessment of their usefulness for marker assisted selection. Theor Appl Genet 103: 1201-1210.

Pellerone FI, Edwards KJ, Thomas MR (2001) Grapevine microsatellite repeats: Isolation, characterisation and use for genotyping of grape germplasm from Southern Italy. Vitis 40: $179-186$.

Pelsy F (2007) Untranslated leader region polymorphism of Tvv1, a retrotransposon family, is a novel marker useful for analyzing genetic diversity and relatedness in the genus Vitis. Theor Appl Genet 116: 15-27.

Pelsy F, Schehrer L, Merdinoglu D 2003. Development of grapevine retrotransposon-based molecular markers (S-SAP). Acta horticulturae 603: 83-87.

Pindo M, Vezzulli S, Coppola G, Cartwright DA, Zharkikh A, Velasco R, Troggio M (2008) SNP high-throughput screening in grapevine using the SNPlex ${ }^{\mathrm{TM}}$ genotyping system. BMC Plant Biol 8: 12.

Rapley R, Harbron S (2004) Molecular analysis and genome discovery. John Wiley, Chichester, UK.

Riaz S, Dangl GS, Edwards KJ, Meredith CP (2004) A microsatellite marker based framework linkage map of Vitis vinifera L. Theor Appl Genet 108: 864-872.

Riaz S, Krivanek AF, Xu K, Walker MA (2006) Refined mapping of the Pierce's disease resistance locus, PdR1, and sex on the extended genetic map of Vitis rupestris $\times$ V. arizonica. Theor Appl Genet 113: 1317-1329.

Riaz S, Tenscher AC, Rubin J, Graziani R, Pao SS, Walker MA (2008) Fine-scale genetic mapping of two Pierce's disease resistance loci and a major segregation distortion region on chromosome 14 of grape. Theor Appl Genet 117: 671-681.

Ritter E, Gebhardt C, Salamini F (1990) Estimation of recombination frequencies and construction of RFLP linkage maps in plants from crosses between heterozygous parents. Genetics 125: 645-654.

Salmaso M, Faes G, Segala C, Stefanini M, Salakhutdinov L, Zyprian E, Toepfer R, Grando MS, Velasco R (2004) Genome diversity and gene haplotypes in the grapevine (V. vinifera L.), as revealed by single nucleotide polymorphisms. Mol Breed 14: 385-395.

Salmaso M, Malacarne G, Troggio M, Faes G, Stefanini M, Grando MS, Velasco R (2008) A grapevine (Vitis vinifera $\mathrm{L}$ ) genetic map integrating the position of 139 expressed genes. Theor Appl Genet 116: 1129-1143.

Scheix T, Gaspin C (1997) Constructing and joining maximum likelihood genetic maps. Proc Int Symp Mol Biol AAI: www.aai.org

Scott KD, Eggler P, Seaton G, Rossetto M, Ablett EM, Lee LS, Henry RJ (2000) Analysis of SSRs derived from grape ESTs. Theor Appl Genet 100: 723-726.

Sefc KM, Regner F, Turetschek E, Glössl J, Steinkellner H (1999) Identification of microsatellite sequences in Vitis riparia and their applicability for genotyping of different Vitis species. Genome 42: 367-373.

Sefc KM, Lopes MS, Lefort F, Botta R, Roubelakis-Angelakis KA, Ibanez J, Pejic I, Wagner HW, Glossl J, Steinkellner H (2000) Microsatellite variability in grapevine cultivars from different European regions and evaluation of assignment testing to assess the geographic origin of cultivars. Theor Appl Genet 100: 498-505. 
Stam P (1993) Construction of integrated genetic-linkage maps by means of a new computer package-Joinmap. Plant J 3: 739-744.

Stam P, van Ooijen JW (1995) JoinMap version 2.0: Software for the calculation of genetic linkage maps. Wageningen, The Netherlands.

Steemers FJ, Weihua Chang W, Grace Lee G, David L Barker DL, Richard Shen R, Kevin L, Gunderson KL (2006) Whole-genome genotyping with the single-base extension assay. Nat Meth 3: 31-33.

Tanksley SD, Young ND, Paterson AH, Bonierbale MW (1989) RFLP maping in plant breedingnew tools for an old science. Biotechnology 7: 257-264.

Thomas MR, Scott NS (1993) Microsatellite repeats in grapevine reveal DNA polymorphisms when analysed as sequence-tagged sites (STSs). Theor Appl Genet 86: 985-990.

Troggio M, Malacarne G, Coppola G, Segala C, Cartwright DA, Pindo M, Stefanini M, Mank R, Moroldo M, Morgante M, Grando MS, Velasco R (2007) A dense single-nucleotide polymorphism based genetic linkage map of grapevine (Vitis vinifera L.) anchoring Pinot noir bacterial artificial chromosome contigs. Genetics 176: 2637-2650.

Tulsieram LK, Glaubitz JC, Kiss G, Carlson JE (1992) Single tree genetic linkage mapping in conifers using haploid DNA from megagametophytes. Biotechnology 10: 686-690.

Van Ooijen JW (2006) JoinMap 4.0, Software for the calculation of genetic linkage maps in experimental populations. Kyazma BV, Wageningen, The Netherlands.

Van Ooijen JW, Voorrips RE (2001) JoinMap 3.0, Software for the calculation of genetic linkage maps. Plant Research International, Wageningen, The Netherlands.

Velasco R, Zharkikh A, Troggio M, Cartwright DA, Cestaro A, Pruss A, Pruss 1 D, Pindo M, FitzGerald LM, Vezulli S, Reid J, Malacarne G, Iliev D, Coppola G, Wardell B, Micheletti D, Macalma T, Facci M, Mitchell JT, Perrazzolli M, Eldredge G, Gatto P, Oyzerski R, Moretto M, Gutin N, Stefanini M, Chen Y, Segala C, Davenport C, Dematte L, Mraz A, Battilana J, Stormo K, Costa F, Tao Q, Si- Ammour A, Harkins T, Lackey A, Perbost C, Taillon B, Stella A, Solovyev V, Fawcett JA, Sterck L, Vandepoele K, Grando SM, Toppo S, Moser C, Lanchbury J, Bogden R, Skolnick M, Sgaramella V, Bhatnagar SK, Fontana P, Gutin A, Van de Peer Y, Salamini F, Viola R (2007) A high quality draft consensus sequence of the genome of a heterozygous grapevine variety. PloS One 2(12) e: 1326 Vezzulli S, Troggio M, Coppola G, Jermakow A, Cartwright D, Zharkikh A, Stefanini M, Grando MS, Viola R, Adam-Blondon AF, Thomas M, This P, Velasco R (2008a) A reference integrated map for cultivated grapevine (Vitis vinifera L.) from three crosses, based on 283 SSR and 501 SNP-based markers. Theor Appl Genet 117: 499-511.

Vezzulli S, Micheletti D, Riaz S, Pindo M, Viola R, This P, Walker MA, Troggio M, Velasco R (2008b) A SNP transferability survey within the genus Vitis. BMC Plant Biol 8: 128.

Vos P, Hogers R, Bleeker M, Reijans M, Vandelee T, Hornes M, Frijters A, Pot J, Peleman J, Kuiper M, Zabeau M (1995) AFLP—a new technique for DNA-fingerprinting. Nucl Acids Res 23: 4407-4414.

Welter LJ, Göktürk-Baydar N, Akkurt M, Maul E, Eibach R, Töpfer R, Zyprian EM (2007) Genetic mapping and localization of quantitative trait loci affecting fungal disease resistance and leaf morphology in grapevine (Vitis vinifera L.). Mol Breed 20: 359-374.

Williams JGK, Kubelik AR, Livak J, Rafalski JA, Tingey SV (1990) DNA polymorphisms amplified by arbitrary primers are useful as genetic markers. Nucl Acids Res 18: 6531-6535.

Xu K, Riaz S, Roncoroni NC, Jin Y, Hu R, Zhou R, Walker MA (2008) Genetic and QTL analysis of resistance to Xiphinema index in a grapevine cross. Theor Appl Genet 116: 305-311.

Zhang J, Hausmann L, Eibach R, Welter LJ, Töpfer R, Zyprian EM (2009). A framework map from grapevine V3125 (Vitis vinifera 'Schiava grossa' x 'Riesling') x rootstock cultivar 'Börner' (Vitis riparia $\mathrm{x}$ Vitis cinerea) to localize genetic determinants of phylloxera root resistance. Theor Appl Genet 119: 1039-1051. 